\title{
CORRECTION
}

\section{Correction to: Metrics of the Aesthetically Perfect Breast}

\author{
Bishara Atiyeh $^{1} \cdot$ Fadel Chahine ${ }^{1}$
}

Published online: 25 September 2018

(C) Springer Science+Business Media, LLC, part of Springer Nature and International Society of Aesthetic Plastic Surgery 2018

\section{Correction to: Aesth Plast Surg (2018) 42:1187-1194}

https://doi.org/10.1007/s00266-018-1154-6

Bishara Atiyeh's name was misspelled in this article. It appears correctly here.

The original article can be found online at https://doi.org/10.1007/ s00266-018-1154-6.

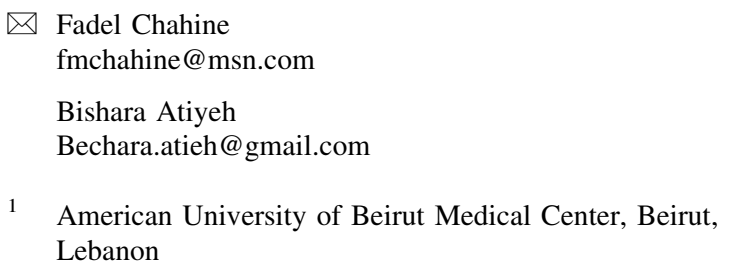

